\title{
Application of Chromatographic and Spectrophotometric Methods for The Analysis of Aliskiren and Hydrochlorothiazide Antihypertensive Combination
}

\author{
Menna I. Ezzeldin ${ }^{1}$, Engy Shokry $^{1}$, Marwa A. Fouad ${ }^{2}$, Ramzia I. Elbagary ${ }^{2} *$

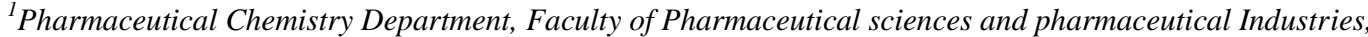 \\ Future University in Egypt \\ ${ }^{2}$ Pharmaceutical Chemistry Department, Faculty of Pharmacy, Cairo University, Kasr El-Aini St., Cairo 11562, Egypt \\ *Corresponding author_E-mail: mano_oon@hotmail.com
}

\begin{abstract}
High performance liquid chromatographic (HPLC) and spectrophotometric methods developed for the simultaneous determination of Aliskiren (ALK) and Hydrochlorothiazide (HCT) combination in bulk powder and in tablets dosage form. Determination of ALK and HCT was achieved by chromatographic separation on Econosphere C-18 column using a mobile phase consisting of water $(\mathrm{pH} 7.5)$ : acetonitrile (50:50) at a flow rate of $0.5 \mathrm{~mL} \cdot \mathrm{min}^{-1}$ and UV detection at $208 \mathrm{~nm}$. Method validation parameters were found to be acceptable over the concentrations range of 5-150 $\mu \mathrm{g} \cdot \mathrm{mL}^{-1}$, 1-50 $\mu \mathrm{g} . \mathrm{mL}^{-1}$ for ALK and HCT respectively. Regarding the spectrophotometric methods, two methods were employed. Simultaneous Equation method, absorbance readings are taken at two wavelengths $277.48 \mathrm{~nm}$ (for ALK) and $267.48 \mathrm{~nm}$ (for HCT) in methanol. Dual Wavelength method, the difference between absorbance readings are taken at two wavelengths $273.3 \mathrm{~nm}, 260 \mathrm{~nm}$ (for Aliskiren) and $270 \mathrm{~nm}, 280 \mathrm{~nm}$ (for HCT) in methanol. The applied spectrophotometric methods were found to be rapid, specific, precise and accurate over the concentration range of 5 $150 \mu \mathrm{g} . \mathrm{mL}^{-1}$ and $1-41 \mu \mathrm{g} . \mathrm{mL}^{-1}$ for ALK and HCT respectively and can be applied for the routine analysis of these drugs in bulk, and combined dosage form without any interference by the excipients.
\end{abstract}

Keywords: High performance liquid chromatography; Simultaneous Equation; Dual Wavelength; Aliskiren; Hydrochlorothiazide.

\section{Introduction}

Aliskiren,(2S,4S,5S,7S)-5-amino-N-(2-carbamoyl-2,2-dimethylethyl) - 4 - hydroxyl - 7 - \{[4-methoxy - 3 - (3 methoxypropoxy)phenyl]methyl -8-methyl-2-(propan-2-yl)nonanamide (Fig. 1a), is an orally active, non-peptide inhibitor of rennin [1]. Hydrochlorothiazide, 6-chloro-3, 4-dihydro-2H-1, 2, 4-benzothiadiazine-7-sulphonamide-1, 1dioxide (Fig. 1b), is a well-known thiazide diuretic commonly used for the treatment of hypertension [2]. The $\mathrm{ALK} / \mathrm{HCT}$ is a direct renin inhibitor and thiazide diuretic combination which is used to achieve simultaneous relaxation of blood vessels and removal of excess body fluid, two processes which help to lower blood pressure and help the heart to pump blood more easily [3].

a)

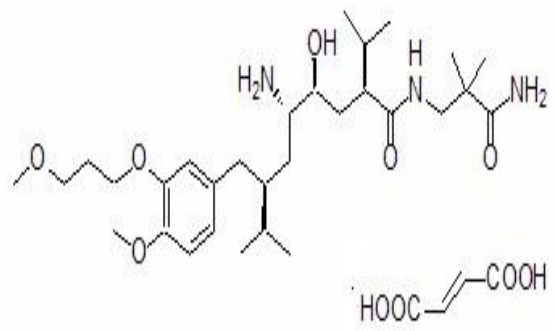

b)<smiles>NS(=O)(=O)c1cc2c(cc1Cl)NCNS2(=O)=O</smiles>

Fig. 1 Structural formula of (a) Aliskiren Hemifurate and (b) Hydrochlorothiazide 
Literature survey revealed the estimation of ALK alone or in combination with other anti-hypertensive agents by HPLC [4], RP-HPLC [5-7] and UV-spectrophotometry [8]. Also, HPLC [9-16] , LC-MS[17], UPLC [18] and UVspectrophotometry [19] methods were reported for the estimation of HCT alone or in combination with other antihypertensive agents. Moreover, several analytical methods have been described in literature for the determination of ALK and HCT in pharmaceutical and biological samples. These methods include HPLC [20,21] and MEKC [22].

In the present work, three different, rapid, sensitive and cost-effective methods, namely HPLC, simultaneous equation and dual wavelength spectrphotometry, were described for the simultaneous determination of ALK and HCT in binary mixture and in pharmaceutical dosage form with subsequent validation of all the proposed methods.

\section{Experimental}

\subsection{Instrumentation}

- The HPLC system is composed of an Agilent Infinity 1260 series HPLC, 1260 Quat pump VL,1260 ALS Autosampler, 1260 TCC (Column heater) and 1260 VWD VL (UV/Viz detector).

- $\quad$ Econosphere C-18 column (150mm x 4.6mm, $5 \mu \mathrm{m})$, Grace company(USA).

- $\quad$ Beckman Coulter DUß 800 Series (USA).

\subsection{Materials and reagents}

All chemicals, solvents and reagents were of analytical or HPLC grade.

- $\quad$ Aliskiren (ALK) (its purity was assessed according to the reported method "spectrophotometrically" and was found to be $99.72 \pm 0.47$ [8]) and Tekturna tablets (Batch. No: F0025, each 1 tablet labeled to contain 150mg Aliskiren and $12.5 \mathrm{mg}$ Hydrochlothiazide) was kindly supplied by Novartis Co., USA..

- Hydrochlorothiazide (HCT) (its purity was assessed according to official method (potentiometery) and was found to be $99.71 \pm 0.44$ [23]), was kindly supplied by Sigma Aldrich, USA.

- $\quad 5 \mathrm{mM}$ Phosphate buffer was kindly supplied by Sigma Aldrich, USA.

- $\quad$ Methanol and acetonitrile were kindly supplied by Sigma Aldrich, USA, of HPLC grade.

\subsection{Stock standard solutions}

ALK and HCT stock solutions $\left(1 \mathrm{mg} \cdot \mathrm{mL}^{-1}\right)$ were prepared by dissolving $100 \mathrm{mg}$ of each standard powder in $100 \mathrm{ml}$ volumetric flask and completed to the mark with methanol.

\subsection{Working standard solutions}

Twenty $\mathrm{ml}$ of ALK and ten $\mathrm{ml}$ of HCT respectively, were transferred from the previously prepared standard stock solution of each, into two separate volumetric flasks $(100 \mathrm{ml})$ and the volumes were completed with selected mobile phase for each selected mixture to get final concentrations $200 \mu \mathrm{g} \cdot \mathrm{mL}^{-1}$ of ALK and $100 \mu \mathrm{g} \cdot \mathrm{mL}^{-1}$ of HCT solutions.

\subsection{Laboratory prepared binary mixture}

A mixture of 6-144 $\mu \mathrm{g} \cdot \mathrm{mL}^{-1}$ ALK, 6-12 $\mu \mathrm{g} \cdot \mathrm{mL}^{-1} \mathrm{HCT}$ were prepared.

\subsection{Dosage forms solution}

Ten Tekturna HCT® tablets were accurately weighed and powdered in a mortar. A quantity of the powdered tablets equivalent to $(150 \mathrm{mg}) \mathrm{ALK}$ and $(12.5 \mathrm{mg}) \mathrm{HCT}$ was extracted with methanol $(3 \times 20 \mathrm{~mL})$ and filtered using Wattman filter paper no. 40 into a $100 \mathrm{~mL}$ volumetric flask. The solution was completed to volume with methanol to obtain a concentration equivalent to $1500 \mu \mathrm{g} \cdot \mathrm{mL}^{-1} \mathrm{ALK}$ and $125 \mu \mathrm{g} \cdot \mathrm{mL}^{-1} \mathrm{HCT}$.

\subsection{The mobile phase}

For ALK and HCT mixture, a mixture of water (adjusted to pH 7.5 with Sodium Hydroxide): acetonitrile (50:50) was prepared. 


\section{Methods}

\subsection{HPLC method}

Accurately measured aliquots of $0.25-7.5 \mathrm{~mL}$ from the $200 \mu \mathrm{g} . \mathrm{mL}^{-1}$ ALK working solution equivalent to 5-150 $\mu \mathrm{g} . \mathrm{mL}$ ${ }^{1} \mathrm{ALK}$ and $0.1-5 \mathrm{~mL}$ from the $100 \mu \mathrm{g} \cdot \mathrm{mL}^{-1} \mathrm{HCT}$ working standard solutions equivalent to1-50 $\mu \mathrm{g} \cdot \mathrm{mL}^{-1} \mathrm{HCT}$, were transferred into two series of $10 \mathrm{~mL}$ volumetric flasks and the volumes were completed with selected mobile phase. Triplicate $10 \mu \mathrm{l}$ samples were autoinjected into the selected column $(150 \mathrm{~mm} \times 4.6 \mathrm{~mm}, 5 \mu \mathrm{m})$ by autosampler and the chromatograms were recorded using the following chromatographic conditions:

- $\quad$ Mobile phase: water (adjusted to $\mathrm{pH} 7.5$ with sodium hydroxide): acetonitrile (50:50).

- $\quad$ Column: Econosphere C-18 column (150mm x 4.6mm, $5 \mu \mathrm{m})$.

- $\quad$ Flow rate : 0.5 mL.min ${ }^{-1}$

- Wavelength : $208 \mathrm{~nm}$

The areas under curve (AUC's) were recorded. Calibration curves were obtained by plotting the area under curve versus the corresponding concentration and the regression equations $(1,2)$ were computed for ALK and HCT, respectively $\mathrm{A}=16.5411 \mathrm{C}+19.5225$

$$
\begin{aligned}
& \mathrm{R}^{2}=0.9999 \text { for } \mathrm{ALK} \\
& \mathrm{R}^{2}=0.9999 \text { for } \mathrm{HCT}
\end{aligned}
$$

\subsection{For spectrophotometric methods}

Accurately measured aliquots of $0.25-7.5 \mathrm{~mL}$ from the $200 \mu \mathrm{g} \cdot \mathrm{mL}^{-1}$ ALK working solution equivalent to $5-150 \mu \mathrm{g} . \mathrm{mL}$

${ }^{-1}$ ALK and 0.1-4.1 mL from100 $\mu \mathrm{g} \cdot \mathrm{mL}^{-1} \mathrm{HCT}$ working standard solutions equivalent to $1-41 \mu \mathrm{g} \cdot \mathrm{mL}{ }^{-1} \mathrm{HCT}$, were transferred into two sets of volumetric flasks $(10 \mathrm{ml})$ and the volumes were completed with methanol.

\subsubsection{Simultaneous Equation method}

The absorption spectrum of each solution was recorded over the range of (200-400 nm) against methanol blank. A calibration curve for each compound was obtained by plotting absorbance (A) against concentration (C). The amplitudes at the peak at $277.48 \mathrm{~nm} \& 267.48 \mathrm{~nm}$ for ALK and HCT respectively, were used in constructing the calibration curves and the regression equations ( $3 \& 4)$ were computed.
$\mathrm{A}=0.0049 \mathrm{C}+0.0098$
$\mathrm{A}=0.0613 \mathrm{C}+0.0418$
$\mathrm{R}^{2}=0.9999$ for ALK
$\mathrm{R}^{2}=0.9999$ for HCT

\subsubsection{Dual Wavelength method}

The absorption spectrum of each solution was recorded over the range of (200-400 nm) against methanol blank. The difference between two absorbencies $273.3 \mathrm{~nm}$ and $260 \mathrm{~nm}$ for ALK and The difference between two absorbencies 270 $\mathrm{nm}$ and $283.3 \mathrm{~nm}$ for HCT, respectively were used in constructing the calibration curves which was obtained by plotting the absorbance difference $(\triangle \mathrm{A})$ against concentration $(\mathrm{C})$ and the regression equations $(5 \& 6)$ were computed.

$\begin{array}{ll}A=0.0025 C-0.0005 & R^{2}=0.9999 \text { for ALK } \\ A=0.0479 C+0.0356 & R^{2}=0.9999 \text { for HCT }\end{array}$

The above two spectrophtometric methods were found to be linear over concentration range of $5-150 \mu \mathrm{g} . \mathrm{mL}^{-1}, 1-41$ $\mu \mathrm{g} . \mathrm{mL}^{-1}$ of ALK and HCT, respectively.

\subsection{Simultaneous determination of laboratory prepared mixtures for (ALK/HCT) and (PER/IND) mixtures using the proposed methods}

Appropriate dilutions of the previous laboratory prepared mixture were treated as previously mentioned under experimental conditions (2.5) for each method. Regarding the HPLC methods, the concentration of each drug in the laboratory prepared mixture using the corresponding regression equation. Regarding simultaneous equation and dual wavelength the concentration of each drug in the laboratory prepared mixture were calculated using the corresponding principle of each method.

\subsection{Simultaneous determination of (ALK/HCT) and (PER/IND) in tablet dosage form using the proposed methods}

Appropriate dilutions equivalent to $60 \mu \mathrm{g} \cdot \mathrm{mL}^{-1} \mathrm{ALK}$ and $5 \mu \mathrm{g} \cdot \mathrm{mL}^{-1} \mathrm{HCT}$ for Tekturna HCT® tablets were transferred from the dosage form solution that previously treated as mentioned under experimental conditions (2.6) for each method, 
were transferred into ten $10 \mathrm{~mL}$ volumetric flasks were for five of those flasks $0.25,0.5,0.75,1$ and $1.25 \mathrm{~mL}$ were accurately transferred from the ALK $200 \mu \mathrm{g} . \mathrm{mL}^{-1}$ working solution, equivalent to 5, 10, 15, 20 and $25 \mu \mathrm{g} \cdot \mathrm{mL}^{-1} \mathrm{ALK}$, were for the other five volumetric flasks $0.5,1,1.5,2$ and $2.5 \mathrm{~mL}$ were accurately transferred from the $\mathrm{HCT}^{100 \mu \mathrm{g} . \mathrm{mL}^{-}}$ ${ }^{1}$ working solution, equivalent to 5, 10, 15, 20 and $25 \mu \mathrm{g} \cdot \mathrm{mL}^{-1} \mathrm{HCT}$. Regarding the HPLC methods, the concentration of labeled and added authentic were calculated using the corresponding regression equation. Regarding simultaneous equation and dual wavelength methods the concentration of labeled and added authentic were calculated using the corresponding principle of each method.

\section{Results and discussion}

\subsection{HPLC method}

Two chromatographic systems including same C18 column $(150 \mathrm{~mm} \times 4.6 \mathrm{~mm}, 5 \mu \mathrm{m})$ and two different mobile phases (acetonitrile: $5 \mathrm{mM}$ sodium phosphate buffer $\mathrm{pH}=7.5$ (50:50)) and (acetonitrile: water $\mathrm{pH}=7.5$ (50:50)) values were attempted with flow rate $1 \mathrm{~mL} \cdot \mathrm{min}^{-1}$. Perfect separated peaks at time $1.168 \mathrm{~min}$ and $1.940 \mathrm{~min}$ for ALK and HCT, respectively were obtained with the same resolution for both mobile phases. In-order to delay the retention time of the first peak of (ALK), and to increase the resolution between the two peaks, flow rate was decreased to $0.5 \mathrm{~mL} . \mathrm{min}^{-1}$ for the selected two mobile phases. Good separation between ALK and HCT with retention time 2.138 min and 3.799 min, respectively, were obtained with same resolution for the two selected mobile phases. Detection was carried out at 208 $\mathrm{nm}$ for ALK and HCT, where high detector sensitivity was achieved as ALK shows a sharp distinct peak at this wavelength while HCT shows a wide absorbance range from $200 \mathrm{~nm}$ to $330 \mathrm{~nm}$. Also, slight changes in $\mathrm{pH}(\mathrm{pH}=7.3$ and $\mathrm{pH}=7.7$ ) had no significant effect on the peaks resolution and the retention time. In-order to avoid the common phosphate buffer problems, the mobile phase consisting of acetonitrile: water (adjusted to $\mathrm{pH} 7.5$ with Sodium Hydroxide) (50:50) at a flow rate $0.5 \mathrm{~mL} \cdot \mathrm{min}-1$ on Econosphere C-18 column (150mmx4.6mm, $5 \mu \mathrm{m}), 208 \mathrm{~nm}$ for ALK and HCT was selected (Fig. 2).

A linear relationship was obtained when the AUCs of ALK and HCT were plotted versus the concentration and equations $(1,2)$ were computed. Method validation parameters were preformed.

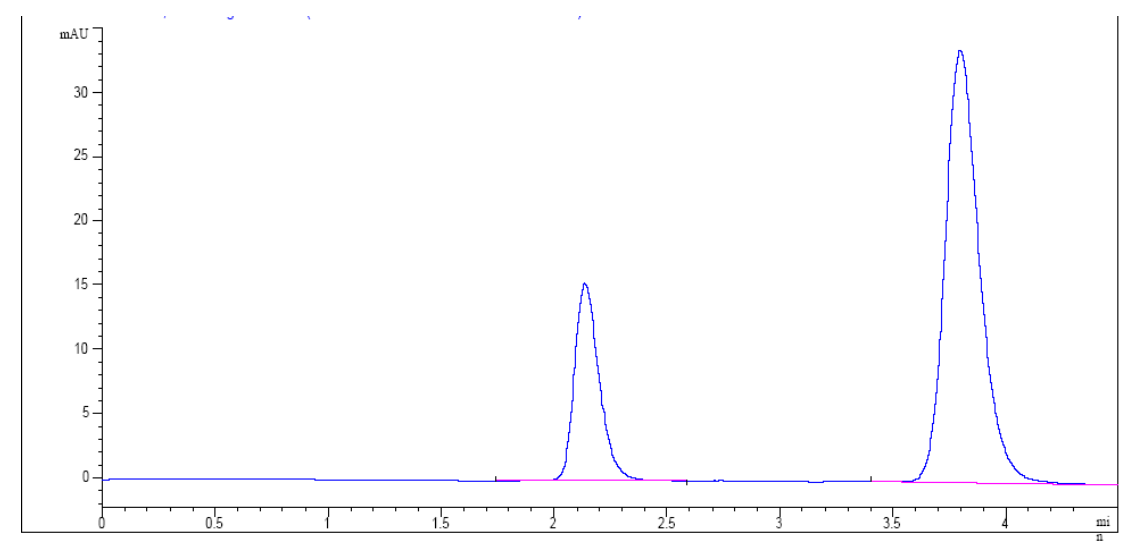

Fig. 2: A typical HPLC chromatogram of $10 \mu \mathrm{L}$ injector of $10 \mu \mathrm{g} \cdot \mathrm{ml}^{-1}$ Aliskiren and $10 \mu \mathrm{g} \cdot \mathrm{ml}^{-1}$ Hydrochlorothiazide mixture.

The method was successfully applied for the quantitative estimation of ALK and HCT in Tekturna ${ }^{\circledR}$ tablets without any interference from additives. Standard addition technique was also applied. Good recoveries have been obtained for the labeled and added drug (Table 1).

\subsection{Spectrophotometric methods}

\subsubsection{Simultaneous Equation spectrophotometric method}

The zero-order spectra of ALK and HCT (Fig. 3) show complete overlapping which prevents the determination of each drug in presence of the other using zero-order spectrophotometry.

In this work, the simultaneous equation method (SE) is presented to solve this problem through measurement of the peak amplitudes at $277.48 \mathrm{~nm} \& 267.48 \mathrm{~nm}$ for ALK and HCT, respectively (Fig. 4) and the concentrations in the sample were obtained at the two selected absorption maxima wavelengths in methanol by using the following equations: 

$\mathrm{C}_{\mathrm{x}}=\underline{\mathrm{A}}_{1} \underline{\mathrm{ay}_{2}}-\mathrm{A}_{\underline{2}} \underline{\mathrm{ay}} \underline{\underline{1}}_{\underline{1}}$ $\mathrm{ax}_{1} \mathrm{ay}_{2}-\mathrm{ax}_{2} \mathrm{ay}_{1}$
$\mathrm{C}_{\mathrm{Y}}=\underline{\mathrm{A}}_{1} \underline{\mathrm{ax}_{2}}-\mathrm{A}_{2} \underline{\mathrm{ax}_{1}}$
$\mathrm{ay}_{1} \mathrm{ax}_{2}-\mathrm{ay}_{2} \mathrm{ax}_{1}$

Where,

$\mathrm{A}_{1}=$ Absorbance of mixture at $\lambda_{\max }$ of $\operatorname{ALK}(277.48 \mathrm{~nm})$

$\mathrm{A}_{2}=$ Absorbance of mixture at $\lambda_{\max }$ of HCT $(267.48 \mathrm{~nm})$

$\mathrm{ax}_{1}=$ absorptivity of ALK at $\lambda_{\max }$ of ALK (277.48 nm)

$\mathrm{ax}_{2}=$ absorptivity of ALK at $\lambda_{\max }$ of HCT $(267.48 \mathrm{~nm})$

ay $_{1}=$ absorptivity of HCT at $\lambda_{\max }$ of ALK $(277.48 \mathrm{~nm})$

$\mathrm{ay}_{2}=$ absorptivity of HCT at $\lambda_{\max }$ of HCT $(267.48 \mathrm{~nm})$

Measurement of the peak amplitudes at $277.48 \mathrm{~nm} \& 267.48 \mathrm{~nm}$ for ALK and HCT, respectively were found to be proportional to the concentration of ALK and HCT over a concentration range $5-150$ and $1-41 \mu$ g.mL ${ }^{-1}$ for ALK and HCT , respectively and the regression equation $(3,4)$ were computed.

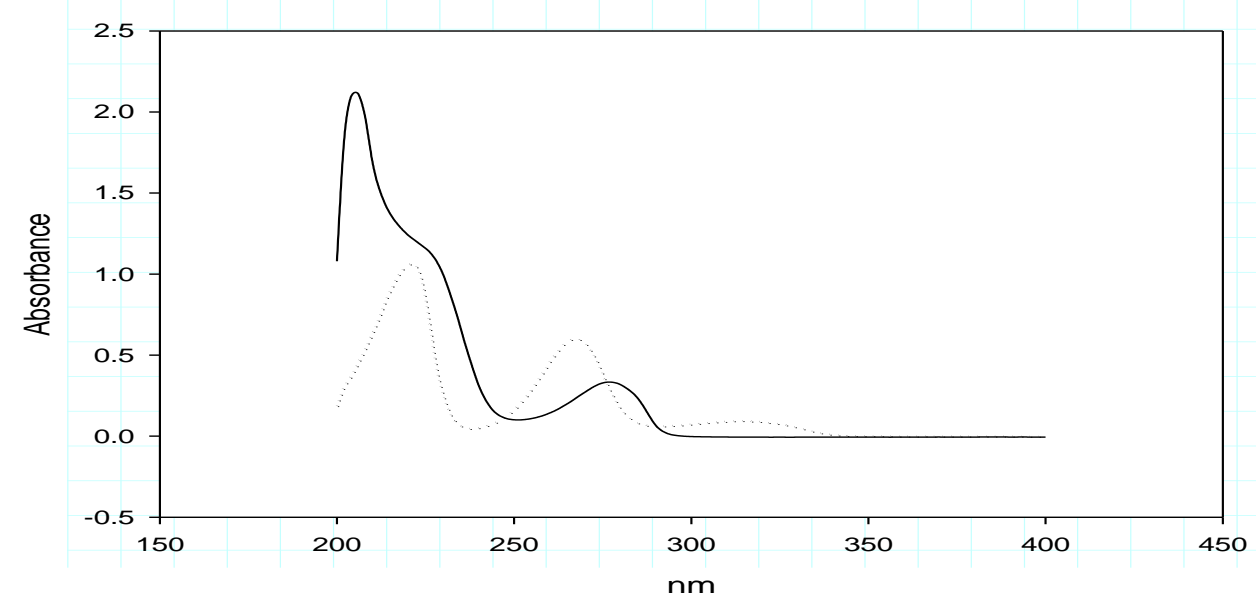

Fig.3: zero-order spectra of $(\leftarrow)$ ALK and (....) HCT, show complete overlapping.

(a)

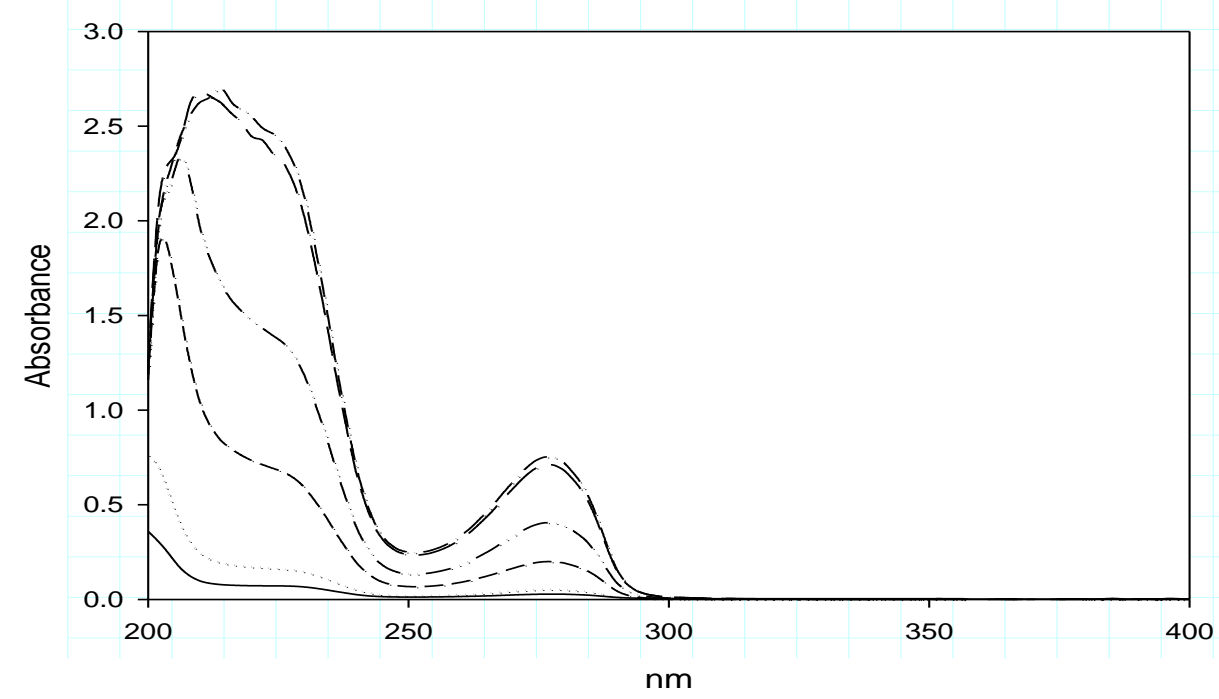


(b)

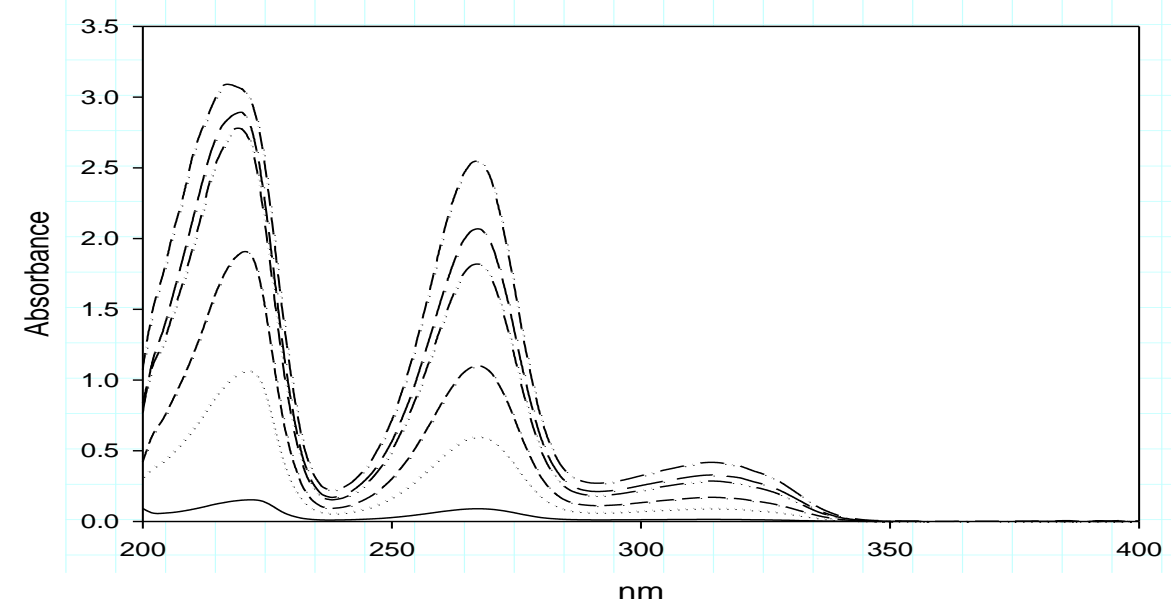

Fig. 4: (a) Aliskirenin methanol (b ) Hydrochlorothiazxide in methanol

The method was tested for selectivity by analyzing laboratory prepared mixtures and the mean percentage recoveries of ALK and HCT are $98.97 \pm 0.309 \& 98.69 \pm 0.358$, respectively.

The method was successfully applied for the quantitative estimation of ALK and HCT in Tekturna $®$ tablets without interference from additives and the standard addition technique was applied. Good recoveries have been obtained for the labeled and added drug.

\subsubsection{Dual Wavelength method}

In this work, the Dual wavelength method (DW) is presented to solve the problem of complete overlapping of The zeroorder spectra of ALK and HCT, as it was observed that ALK shows the same absorbance at wavelengths of $270 \mathrm{~nm}$ and $283.3 \mathrm{~nm}$ and HCT shows marked difference of absorbance at these two wavelengths, while HCT shows same absorbance at wavelengths of $273.3 \mathrm{~nm}$ and $260 \mathrm{~nm}$ and ALK shows marked difference of absorbance at these two wavelengths (Fig. 5). Absorbance difference values were recorded at respective set of two wavelengths and calibration curve was plotted between concentration and absorbance difference values for both drugs and the regression equation ( 5 , 6) were computed.

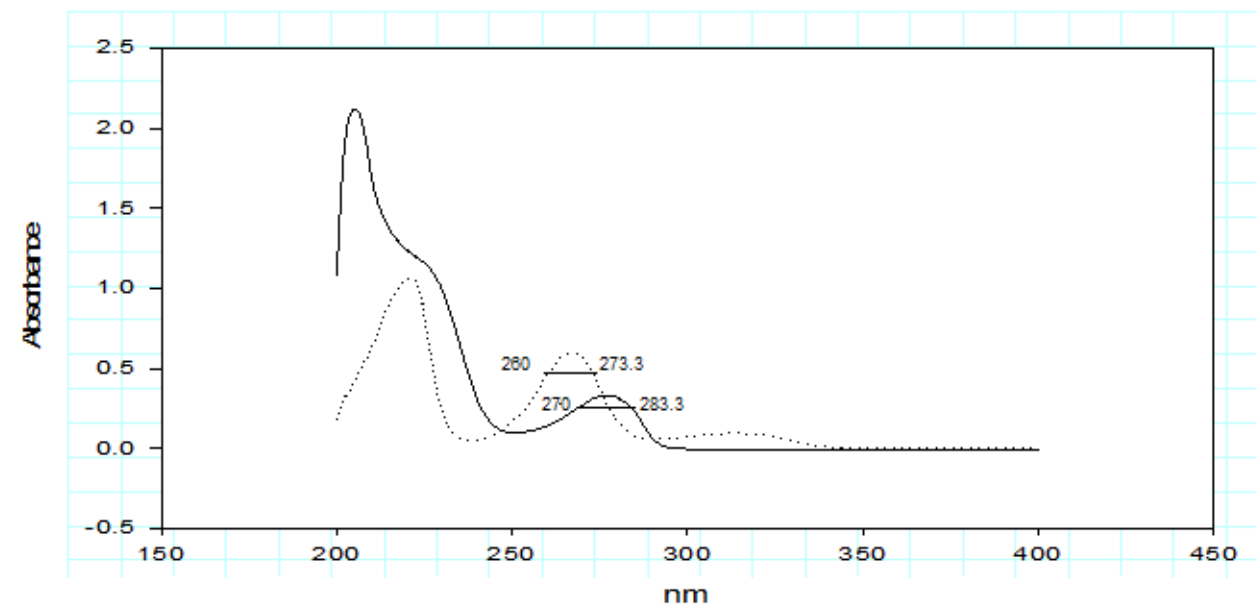

Fig_5: zero-order spectra of ( ) ALK and (....) HCT.

The method was tested for selectivity by analyzing laboratory prepared mixtures and the mean percentage recoveries of ALK and HCT are $100.00 \pm 0.588 \& 99.39 \pm 0.425$, respectively.

The method was successfully applied for the quantitative estimation of ALK and HCT in Tekturna ${ }^{\circledR}$ tablets without interference from additives and the standard addition technique was applied. Good recoveries have been obtained for the labeled and added drug. 


\section{Method validation}

The validation of the methods was assessed by estimation of linearity, accuracy, selectivity, intraday and interday variations \pm (RSD) and application of pharmaceutical preparation and further assessed by applying standard addition technique as shown in Table (1).

\section{1 Linearity range}

Under the experimental conditions, calibrations for ALK and HCT show linear relationship and regression equations data were shown in Table (1).

\subsection{Accuracy}

It was determined by applying the proposed methods on at least five different concentrations within the linearity range for drug substance and pharmaceutical dosage forms. The percentage relative standard deviation revealed high accuracy Table (1).

\subsection{Precision}

For evaluation of the intraday precision, results of three replicate analyses of three different concentrations of ALK and HCT were calculated on a single day. The interday precision was calculated from the freshly prepared samples with the same concentration analyzed on three different days. The percentage relative standard deviations ( RSD \%) indicating the repeatability and reproducibility of the proposed method Table (1).

\subsection{Specificity}

Specificity of the proposed methods were tested by the assay of ALK and HCT mixtures in different concentrations and the mean percentage recoveries of each drug was calculated using the corresponding regression equation and the results were listed in Table (1).

\subsection{Method validation of dosage forms}

The validity of the proposed method was assessed by assay of the pharmaceutical dosage forms and applying the standard addition technique within the linearity range of the three methods and the results were shown in Table(1) revealing the selectivity.

Table1. Analytical and validation data for the determination of ALK and HCT mixture by the proposed methods

\begin{tabular}{|c|c|c|c|c|c|c|}
\hline \multirow{3}{*}{ Parameters } & \multicolumn{6}{|l|}{ Methods } \\
\hline & \multicolumn{2}{|c|}{ Simultaneous Equation method } & \multicolumn{2}{|c|}{ Dual Wavelength method } & \multicolumn{2}{|l|}{ HPLC } \\
\hline & ALK & HCT & ALK & HCT & ALK & HCT \\
\hline Wave length, $\lambda(\mathrm{nm})$ & 277.48 & 267.48 & $273.3-260$ & $270-283.3$ & 208 & 208 \\
\hline Linearity range $(\mu \mathrm{g} / \mathrm{ml})$ & $5-150$ & $1-41$ & $5-150$ & $1-41$ & $5-150$ & $1-50$ \\
\hline Intercept & 0.009 & 0.0417 & -0.0005 & 0.0356 & 19.522 & 45.184 \\
\hline SE of intercept & 0.001 & 0.007 & 0.0008 & 0.0074 & 8.758 & 10.232 \\
\hline Slope & 0.005 & 0.0613 & 0.0024 & 0.0479 & 16.541 & 58.276 \\
\hline SE of Slope & $1.672 \mathrm{E}-05$ & 0.0002 & $1.125 \mathrm{E}-05$ & 0.0002 & 0.085 & 0.334 \\
\hline Regression coefficient $\left(\mathrm{r}^{2}\right)$ & 0.9999 & 0.9999 & 0.9999 & 0.9999 & 0.9999 & 0.9999 \\
\hline Residual SS & $3.125 \mathrm{E}-05$ & 0.0004 & 7.857E-06 & 0.00039 & 458.484 & 819.940 \\
\hline \multicolumn{7}{|c|}{ Accuracy $^{(\mathrm{a})}($ mean $\pm \mathrm{RSD} \%)$} \\
\hline Bulk & $100.08 \pm 0.154$ & $100.01 \pm 0.181$ & $99.99 \pm 0.207$ & $100.07 \pm 0.149$ & $100.22 \pm 0.242$ & $100.87 \pm 0.111$ \\
\hline Dosage Form & $100.17 \pm 0.688$ & $99.08 \pm 0.655$ & $99.63 \pm 0.650$ & $99.48 \pm 0.660$ & $100.21 \pm 0.616$ & $100.72 \pm 0.677$ \\
\hline Standard addition & $99.97 \pm 0.209$ & $100.08 \pm 0.208$ & $100.18 \pm 0.275$ & $100.11 \pm 0.297$ & $100.01 \pm 0.298$ & $99.96 \pm 0.254$ \\
\hline \multicolumn{7}{|l|}{ Precision $^{(\mathrm{b})}($ mean \pm RSD $\%)$} \\
\hline Inter - day & $100.12 \pm 0.324$ & $99.98 \pm 0.335$ & $99.98 \pm 0.313$ & $100.40 \pm 0.313$ & $100.45 \pm 0.303$ & $100.43 \pm 0.326$ \\
\hline Intra - day & $99.97 \pm 0.223$ & $100.00 \pm 0.197$ & $100.06 \pm 0.255$ & $100.22 \pm 0.222$ & $100.37 \pm 0.236$ & $100.37 \pm 0.289$ \\
\hline Specificity & $98.97 \pm 0.308$ & $98.69 \pm 0.358$ & $100.00 \pm 0.588$ & $99.39 \pm 0.425$ & $100.50 \pm 0.561$ & $100.07 \pm 0.369$ \\
\hline
\end{tabular}

(a) Mean of five different experiments

(b) Mean of nine different experiments 


\section{Conclusion}

The proposed methods are valid, simple and selective and could be used in quality control laboratories for the determination of the cited drugs in drug substance and pharmaceutical product where economy and saving time are essential.

\section{References}

[1] AustarlianGovernment,Department of Health and AegingTheraputic Goods Adminstration Submission No: PM-2008-2072-3.(Obtained via online)..

[2] AustarlianGovernment, Department of Health and AegingTheraputic Goods Adminstration Submission No: PM-2008-2072-3. (Obtained via online).

[3] Drugs information online. Drugs.com. (obtained via online).

[4] Shalinipachauri, Sarveshpaliwal, K. S. Srinivas, Y. Singh`V. Jain. Development \& validation of HPLC method for analysis of some antihypertensive agents in their pharmaceutical dosage forms. Journal of Pharmaceutical sciences and Research. 2 (2010) 464-459.

[5] M.W. Sangoi, M.S. Sangoi, P.R. Oliveira, L.T. Secretti, and C.M.B. Rolim. Determination of aliskiren in tablet dosage forms by a validated stability indicating RP-LC method. Journal of Chromatographic Science, 49 (2011) 170-175

[6] G. K. Swamy , J.V.L.N S. Rao, J.M. R. Kumar‘ U. A. Kumar, D.V.R.N. Bikshapathi, D.V. Kumar. Ana-lytical method development and validation of aliskiren in bulk and tablet dosage form by RP-HPLC method. Journal of Pharmacy Research , 4 (2011) 865-867.

[7] K. S. Babu, J.V.L.N.S. Rao, and K. V. Bhargava. A simple and sensitive method for the determination of aliskiren hemifumarate using HPLCUV detection. Rasayan Journal Chemistry, 4 (2011) 285-288.

[8] W. Sangoi, L. T. Secretti. Development and validation of an UV spectrophotometric method for the determination of aliskiren in tablets. Isabel FraçãoDiefenbach e Clarice MadalenaBuenoRolim. Quim. Nova, 33 (2010) 1330-1334.

[9] V.ulvi and H. keski-hynnil. First-derivative UV spectrophotometric and high performance liquid chromatographic analysis of some thiazide diuretics in the presence of their photodecomposition products. Journal of Pharmaceutical \& Biomedical Analysis, 12 (1994) 917-922.

[10] A. F. M. E1 Walily, S. F. Belal, E. A. Heaba, A. E. Kersh. Simultaneous determination of enalapril maleate and hydrochlorothiazide by firstderivative ultraviolet spectrophotometry and HPLC. Journal of Pharmaceutical and Biomedical Analysis 13 (1995) 851-856.

[11] E. Banoglu, Yalc, ýn, zkan, O. Atay. Dissolution tests of benazepril-HCL and hydrochlorothiazide in commercial tablets: comparison of spectroscopic and high performance liquid chromatography methods. Il Farmaco 55 (2000) 477-483.

[12] E. Satana, S. Altýnay, N. G. Goger, S. A. Ozkan،Z. Senturk. Simultaneous determination of valsartan and hydrochlorothiazide in tablets by first-derivative ultraviolet spectrophotometry and LC. Journal of Pharmaceutical and Biomedical Analysis 25 (2001) 1009-1013.

[13] V.P. Rane, J.N. Sangshetti, and D.B. Shinde. Simultaneous High-Performance Liquid Chromatographic Determination of Telmisartan and Hydrochlorothiazide in Pharmaceutical Preparation. Journal of Chromatographic Science, 46 (2008)887-891.

[14] J. A. Kumar, A. Sathya, K. S. Kumar, N. Patilsagar, B. Prathap, S.B. Lokesh, V. Gopal. Simultaneous estimation of olmesartan medoxomil and hydrochlorothiazide by RP-HPLC method from combined dosage forms. Int. J. Res. Pharm. Sci. 1 ( 2010)24-27.

[15] S. J. Joshi,P. A. Karbharia, Suvarna, I. Bhoira, K.S.Bindub, C. Dasc. RP-HPLC method for simultaneous estimation of bisoprolol fumarate and Hydrochlorothiazide in tablet formulation. Journal of Pharmaceutical and Biomedical Analysis، 52 (2010) 362-371.

[16] N. Erk. Analysis of binary mixtures of losartan potassium and hydrochlorothiazide by using high performance liquid chromatography, ratio derivative spectrophotometric and compensation technique. Journal of Pharmaceutical and Biomedical Analysis 24 (2001) 603-611.

[17] F.Gao, M. Zhang, X. Cui, Z. Wang، Y. Sun, J. Gu. Simultaneous quantitation of hydrochlo-othiazide and metoprolol in human plasma by liquid chromatography-tandem mass spectrometry. Journal of Pharmaceutical and Biomedical Analysis, 52 (2010) 149-154.

[18] Santajinalwade, Vangalarangareddy, Dantudurgarao, Inabathinakoteswararao. Rapid simultaneous determination of telmisartan‘ amlodipine besylate and hydrochlorothiazide in a combined poly pill dosage form by stability-indicating ultra performance liquid chromatography. Sci Pharm.79 (2011) 69-84.

[19] A. M. Raja, D. Selvakumar. Method development and validation of hydrochlorothiazide in tablet dosage form by UV spectroscopy. Int. J. Res. Pharm. Sci., 1 (2010) 369-371.

[20] M. S. Sangoia, M.W. Sangoib, P. R. Oliveirac, V. Todeschinia and C. M. B. Rolim . Rapid simultaneous determination of Aliskiren and Hydrochlorothiazide from their pharmaceutical formulation by monolithic silica HPLC column employing experimental designs. Journal of Liquid Chromatography \& Related Technologies, 34(2011) 1976-1996.

[21] V. P. Choudhari, N. A. Bari, A.Shah , S. N. Sharma, P. M. Katariya, S. S. Bhise. Simultanious estimayion of Aliskiran and Hydrochlorothiazide in pharmaceutical formulation by RP-LC-PDA. Int. J. Pharm. Sci. Rev. Res., 14 (2012) 10-14.

[22] M. S. Sangoi ,M. W. Sangoib, P. R. Oliveira, C. M. B. Rolim, M. Steppe. Simultaneous determination of aliskiren and hydrochlorothiazide from their pharmaceutical preparations using a validated stability-indicating MEKC method. Journal of Separation Science 34(2011) 18591866.

[23] British Pharmacopeia, Her Majesty's Stationary office, London, 2012, p.1073. 